\title{
Surgical Treatment Outcome of Salivary Gland Tumors
}

\author{
Nibrass J. Kadhim B.D.S (1) \\ Salwan Y. Bede B.D.S, F.I.B.M.S (2)
}

\begin{abstract}
Background: Salivary gland neoplasms constitute a group of heterogeneous lesions with complex clinicopathologic characteristics and distinct biological behavior. Numerous studies have suggested geographical variation, therefore the aims of this study were to analyze the characteristics of salivary gland neoplasms in two Iraqi centers and to analyze the postoperative complications that are encountered after surgical treatment of these tumors.

Materials and Methods: A retrospective study of the patients who were treated for major and minor epithelial salivary gland tumors was conducted. The analyzed data included; demographic information lage and gender), the site of the tumor, the clinical manifestations, the histological type of the tumor, the type of the treatment and the postoperative complications.

Results: Fifty seven patients were included in this study. The parotid gland was involved in most patients ( $\mathrm{n}=37$, $64.9 \%)$. Thirty five patients (61.4\%) had benign tumors while 22 patients (38.6\%) had malignant tumors. The mean age of patients with malignant tumors was 52.05 ( \pm 17.3$)$ while of patients diagnosed with benign tumors was $41.6( \pm 11.4)$ years, the difference was statistically significant $(p=0.008)$. Surgical treatment consisted of superficial parotidectomy, total parotidectomy, surgical excision of the submandibular gland, surgical excision of minor salivary glands and maxillectomy. The most common complication was weakness of one or multiple branches of the facial nerve, complications were significantly associated with patients' age, whereas gender and type of tumor whether benign or malignant did not affect the complication rate

Conclusions: benign salivary gland tumors are more common than malignant tumors with no gender predilection and that patients who are diagnosed with malignant tumors are significantly older that patients with benign tumors, parotid gland is the most commonly affected gland with pleomorphic adenoma as the most frequent diagnosis. Facial nerve dysfunction was the most common complication and the complication rate was significantly associated with the age of patients.
\end{abstract}

Key words: outcome; salivary gland tumors; surgical treatment. (Received: 7/1/2019; Accepted 10/2/2019)

\section{INTRODUCTION}

Salivary gland neoplasms constitute 2$10 \%$ of all head and neck neoplasms; they consist of a group of heterogeneous lesions with complex clinicopathologic characteristics and distinct biological behavior. ${ }^{(1,2)}$

Salivary gland tumors are divided into epithelial and non-epithelial as well as into benign and malignant tumors, Spiro in $1986^{(3)}$ in a study of 2807 patients reported that $25 \%$ of parotid tumors, $43 \%$ of submandibular gland tumors and $82 \%$ of minor salivary gland tumors were malignant. In a recent study of 7190 Chinese patients, malignant parotid, submandibular, sublingual and minor salivary gland tumors were reported in $22.26 \%$, $35.76 \%, 92.97 \%$, and $61.89 \%$ of the cases respectively. ${ }^{(4)}$

(1)Board student, Oral and Maxillofacial Surgery Unit, Ghazi Al-hariri Hospital for Surgical Specialties

(2)Assistant Professor, Department of Oral and Maxillofacial Surgery, College of Dentistry, University of Baghdad.
Studies have shown that the parotid gland is the most common site of occurrence ranging from about $60 \%$ to $70 \%$ of the cases followed by minor salivary glands $(22 \%-24 \%)$, whereas $8 \%$ to $10 \%$ of these tumors involve the submandibular gland. The least common site for these tumors is the sublingual gland with a percentage ranging from less than $1 \%$ to about $2.5 \%$. ${ }^{(3-5)}$

Numerous studies from different regions of the world have been published concerning the incidence and the histological types of salivary gland tumors and geographical variation has been suggested, ${ }^{(1,6)}$ therefore the aims of this study were to analyze the characteristics of salivary gland neoplasms in two Iraqi centers and to analyze the postoperative complications that are encountered after surgical treatment of these tumors.

\section{MATERIALS AND METHODS}

The medical records of the patients who were treated for major and minor salivary gland tumors at the Oral and Maxillofacial surgery units of Al-Yarmouk Teaching Hospital and 
Ghazi Al-hariri Hospital for Surgical Specialties during the period from March 2016 to September 2017 were retrospectively reviewed.

Diagnosis was based on history, clinical examination, imaging which included ultrasonography, CT scans and MRI and other investigations such as fine needle aspiration biopsy (FNAB) and incisional biopsy which was performed for minor salivary gland tumors. Patients who were diagnosed with non-epithelial tumors were excluded from this study.

The retrieved and analyzed data included; demographic information (age and gender), the site of the tumor, the clinical manifestations, the histological type of the tumor, the type of the treatment and the postoperative complications.

Statistical analysis was performed using GraphPad Prism version 6 for Windows (GraphPad Software, La Jolla, CA, USA). For descriptive analysis percentages and mean \pm standard deviation (SD) were recorded. The data were analyzed statistically using student $t$-test, Chi square test or Fischer's exact test. The difference was considered significant at $\mathrm{P}<0.05$.

\section{RESULTS}

Fifty seven patients with an age range of 20-85 years and a mean age $( \pm$ SD) of $45.4( \pm 14.6)$ years were enrolled in this study. The patients consisted of $29(50.9 \%)$ males and $28(49.1 \%)$ females. The mean age $( \pm$ SD) of males was $46.97( \pm 13.95)$ and of females was $43.68( \pm$ 15.32), the age difference between both genders was statistically not significant $(\mathrm{p}=$ $0.4)$.

The parotid gland was involved in most of the patients $(n=37,64.9 \%)$, followed by minor salivary gland $(\mathrm{n}=17,29.8 \%)$ and submandibular glands $(\mathrm{n}=3,5.3 \%)$. Parotid tumors

Swelling was the most common clinical presentation; it was manifested in all patients $(100 \%)$. Seven patients $(12.3 \%)$ showed facial nerve weakness of one or multiple branches of the facial nerve and in 8 patients $(14 \%)$ there was tethering of the tumor to the overlying skin.

Thirty five patients $(61.4 \%)$ were diagnosed with benign tumors ( 24 in the parotid, 3 in the submandibular and 8 in the minor salivary glands) while 22 patients (38.6\%) had malignant tumors (13 in the parotid and 9 in the minor salivary glands); the histological types of the tumors are summarized in (Table 1).

Table 1: Histological types of the benign and malignant tumors

\begin{tabular}{|l|c|c|}
\hline $\begin{array}{l}\text { Histological types of the } \\
\text { tumors }\end{array}$ & $\begin{array}{l}\text { Number of } \\
\text { patients } \\
(\mathbf{n = 5 7})\end{array}$ & $\%$ \\
\hline Benign tumors (n=35) & \multicolumn{2}{|l|}{} \\
\hline Pleomorphic adenoma & 31 & 54.4 \\
\hline Oncocytoma & 2 & 3.5 \\
\hline Basal cell adenoma & 2 & 3.5 \\
\hline Malignant tumors (n=22) \\
\hline $\begin{array}{l}\text { Mucoepidermoid } \\
\text { carcinoma }\end{array}$ & 9 & 15.8 \\
\hline Adenoid cystic carcinoma & 5 & 8.8 \\
\hline Acinic cell carcinoma & 5 & 8.8 \\
\hline Ductal carcinoma & 2 & 3.5 \\
\hline $\begin{array}{l}\text { low grade polymorphous } \\
\text { adenocarcinoma }\end{array}$ & 1 & 1.7 \\
\hline
\end{tabular}

The mean age of patients who were diagnosed with malignant tumors was $52.05( \pm 17.3)$ years compared with the mean age of patients diagnosed with benign tumors which was 41.6 $( \pm 11.4)$ years, the difference was statistically significantly $(\mathrm{p}=0.008)$. With respect to the differences in gender distribution and site of tumors the results were statistically not significant (Table 2).

Table 2: Distribution according to gender and site of tumors in patients with benign and malignant tumors

\begin{tabular}{|c|c|c|c|}
\hline Variables & $\begin{array}{l}\text { Benign } \\
\text { tumors } \\
(n=35)\end{array}$ & $\begin{array}{l}\text { Malignant } \\
\text { tumors } \\
(n=22)\end{array}$ & $\begin{array}{l}P \\
\text { value }\end{array}$ \\
\hline Gender & & & \multirow{3}{*}{$\begin{array}{c}0.2829 \\
* \\
{[\mathrm{NS}]}\end{array}$} \\
\hline Male & $20(69 \%)$ & $9(31 \%)$ & \\
\hline Female & $\begin{array}{l}15 \\
(53.6 \%)\end{array}$ & $13(46.4 \%)$ & \\
\hline \multicolumn{4}{|l|}{$\begin{array}{l}\text { Site of the } \\
\text { tumor }\end{array}$} \\
\hline $\begin{array}{l}\text { Major } \\
\text { salivary } \\
\text { glands }\end{array}$ & $\begin{array}{l}27 \\
(67.5 \%)\end{array}$ & $\begin{array}{l}13 \\
(32.5 \%)\end{array}$ & \multirow{2}{*}{$\begin{array}{c}0.2338 \\
* \\
{[\mathrm{NS}]}\end{array}$} \\
\hline $\begin{array}{l}\text { Minor } \\
\text { salivary } \\
\text { gland }\end{array}$ & $8(47 \%)$ & $9(53 \%)$ & \\
\hline
\end{tabular}

* Fishers exact test, NS: Not significant 
Surgical treatment consisted of superficial parotidectomy in 31 patients $(54.4 \%)$; 23 for benign tumors and 8 for malignant tumors. Total parotidectomy was required in 6 patients $(10.5 \%) ; 1$ for benign tumor and 5 for malignant tumors. Surgical excision of the submandibular gland was performed for 3 patients $(5.3 \%)$ who had benign tumors. For minor salivary gland tumors 14 patients $(24.6 \%)$ the surgical treatment consisted of surgical excision; this was carried out for 8 patients with benign tumors and 6 patients with malignant tumors. In 3 patients $(5.3 \%)$ maxillectomy was performed for malignant tumors involving the hard palate. Neck dissection was performed in one patient with high grade mucoepidermoid carcinoma of minor salivary gland origin.

Apart from postoperative pain and swelling which occurred in all patients, postoperative complications were identified in $(17 / 56$, $30.4 \%$ ) patients. The most common complication was weakness of one or multiple branches of the facial nerve in patients who did not manifest facial nerve weakness preoperatively; this was evident in $(12 / 50$, 24\%) patients of which 9 patients showed recovery of the neural function within 1 to 4 months postoperatively and 3 were regarded as permanent damage as they demonstrated no recovery after 6 months postoperatively. The other complications included infection and wound dehiscence in 2 patients (3.6\%), hematoma formation in 1 patient $(1.8 \%)$, seroma formation in 1 patient $(1.8 \%)$ and unsightly hypertrophic scar in 1 patient $(1.8 \%)$. Death in the early postoperative period occurred in one 76 old male patient who had undergone total parotidectomy for adenoid cystic carcinoma making the mortality rate in this series $(1.7 \%)$.

Complications were significantly associated with patients' age, whereas gender and type of tumor whether benign or malignant did not affect the complication rate (Table 3). All complications were reported after parotid surgery; total parotidectomy was associated with $100 \%$ complication rate whereas superficial parotidectomy was associated with $38.7 \%(\mathrm{n}=12)$.
Table 3: Factors affecting complication rate (excluding death, $n=56$ )

\begin{tabular}{|c|c|c|c|}
\hline Variable & Complications & $\begin{array}{c}\text { No } \\
\text { complications }\end{array}$ & $\begin{array}{c}P \\
\text { value }\end{array}$ \\
\hline $\begin{array}{l}\text { Age } \\
\text { (mean } \pm \\
\text { SD) }\end{array}$ & $50 \pm 11.45$ & $42.5 \pm 14.7$ & $\begin{array}{l}0.04 \\
\dagger[\mathrm{S}]\end{array}$ \\
\hline \multicolumn{4}{|l|}{ Gender } \\
\hline Male & 9 & 19 & \multirow{2}{*}{$\begin{array}{l}0.77 \\
+[\mathrm{NS}]\end{array}$} \\
\hline Female & 8 & 20 & \\
\hline \multicolumn{4}{|c|}{ Type of tumor } \\
\hline Benign & 9 & 26 & \multirow{2}{*}{$\begin{array}{c}0.54 \\
\pm[\mathrm{NS}]\end{array}$} \\
\hline Malignant & 7 & 14 & \\
\hline $\begin{array}{l}\dagger t \text {-test for } \\
+ \text { Chi squar } \\
\text { S: Significa } \\
\text { NS: Not sig }\end{array}$ & $\begin{array}{l}\text { independent mea } \\
\text { test } \\
\text { at. } \\
\text { nificant }\end{array}$ & & \\
\hline
\end{tabular}

\section{DISCUSSION}

Salivary gland tumors are large and diverse group of lesions, characterized by complex clinicopathological features and distinct biological behavior. (1) The annual global incidence reported in the literature is variable ranging from 0.4 to less than 15 cases per 100000 people ${ }^{(1,7)}$ and geographic and racial factors have been reported to influence the incidence. ${ }^{(8)}$

This study aimed to evaluate the major characteristics of salivary gland tumors in terms of demographic characteristics, histopathological diagnosis, types of surgical treatment, complications and recurrence rates in two centers in Baghdad.

The mean age of patients in this study (45.4 years) is in line with that reported in other studies. ${ }^{(1,8,9)}$ The WHO in 2005 reported that the average ages of patients with benign and malignant tumors are 46 and 47 years, respectively, ${ }^{(10)}$ in this study, patients with benign tumors were significantly younger than the patients diagnosed with malignant tumors which is in line with many studies. ${ }^{(\mathbf{1}, \mathbf{6}, \mathbf{8})}$

The gender distribution was even in this study which is in keeping with other studies. ${ }^{(11)}$ In general females are more frequently affected by salivary gland tumors but there is some gender variation according to the tumor type, (10) many studies have demonstrated that benign tumors were slightly more common in 
females, whereas malignancies more often occur in males, ${ }^{(\mathbf{1})}$ this was not demonstrated in this study.

With respect to the site distribution this study revealed that the parotid gland was the most common site $(64.9 \%)$ followed by minor salivary gland $(29.8 \%)$ which is in line with other studies. ${ }^{(12,13)}$ The distribution of parotid gland tumors in this study is within the range reported by the WHO (64-80\%), whereas the incidence of minor salivary gland tumors in this study is higher than that reported by the WHO (9-23\%), yet for submandibular gland tumors the incidence reported in this study $(5.3 \%)$ is lower than that demonstrated by the WHO (7-11\%). ${ }^{(3,10)}$

Sublingual gland tumors were not encountered in this study most likely due to the rarity of these tumors, ${ }^{(6)}$ it is estimated that about $1 \%$ of salivary gland tumors affect the sublingual gland. ${ }^{(10,14)}$

This study showed that benign salivary gland tumors are more common than the malignant tumors, a finding that is well documented in the literature, the incidence of benign and malignant tumors, in this study, is within the range reported by the WHO being (54-79\%) and $(21-46 \%)$ respectively. (10) However, comparing with the results of other studies from different parts of the world, (1, 6, 8) patients in this study showed higher incidence of malignant tumors, this could be attributed to geographic variation.

Pleomorphic adenoma was the most common benign tumor and mucoepidermoid carcinoma was the most common malignant tumor followed by Adenoid cystic carcinoma with predilection to minor salivary glands which is also demonstrated in other studies. ${ }^{(\mathbf{1 5}, \mathbf{1 6})}$

In this study all complications where encountered after treatment of parotid tumors and total parotidectomy was associated with the highest complication rate; this can be attributed to the aggressiveness of the intervention which seems to be a risk factor for development of complications, less aggressive interventions such as extracapsular dissection have been found to reduce the frequency of complications compared to the standard procedures. ${ }^{(17)}$ The most common postoperative complication was postoperative facial nerve dysfunction which is in keeping with other studies. ${ }^{(\mathbf{1 8}, \mathbf{1 9})}$ The complication rate was significantly associated with age being more in older patients whereas other variables namely; gender and type of tumor, did not affect the complication rate.

Despite the small sample size in this study, it can be concluded that benign salivary gland tumors are more common than malignant tumors with no gender predilection and that patients who are diagnosed with malignant tumors are significantly older that patients with benign tumors, parotid gland is the most commonly affected gland with pleomorphic adenoma as the most frequent diagnosis. Complications were encountered after parotid surgery with higher incidence after total than partial parotidectomies and that facial nerve dysfuction was the most common complication and the complication rate was significantly associated with the age of patients.

\section{REFERENCES}

1. Fonseca FP, Carvalho MV, Almeida OP, Rangel ALCA, Takizawa MCH, Bueno AG, Vargas PA. Clinicopathologic analysis of 493 cases of salivary gland tumors in a Southern Brazilian population. Oral Surg Oral Med Oral Pathol Oral Radiol 2012;114:230-239

2. Bradley P, O'Hara J, Diseases of the salivary glands. Surgery (Oxford) 2012; 30(11): 611-616 DOI: 10.1016/j.mpsur.2012.09.006.

3. Spiro RH. Salivary neoplasms: overview of a 35year experience with 2807 patients. Head Neck Surg 1986; 8:177-84.

4. Gao M, Hao Y, Huang MX, Ma DQ, Chen Y, Luo HY, Gao Y, Cao ZQ, Peng X, Yu GY. Salivary gland tumours in a northern Chinese population: a 50- year retrospective study of 7190 cases. Int J Oral Maxillofac Surg. 2017; 46: 343349.

5. Mandel L. Salivary gland disorders. Med Clin N Am 2014; 98: 1407-1449

6. Wang X-d, Meng L-j, Hou T-t, Huang S-h. Tumours of the salivary glands in northeastern China: a retrospective study of 2508 patient. Br J Oral Maxillofac Surg. 2015; 53: 132-137.

7. Seethala RR. Salivary Gland Tumors Current Concepts and Controversies. Surg Pathol Clin. 2017; 10: 155-176

8. Ansari MH. Salivary Gland Tumors in an Iranian Population: A Retrospective Study of 130 Cases. J Oral Maxillofac Surg 2007; 65: 2187-2194.

9. de Oliveira FA, Duarte EC, Taveira CT, Máximo AA, de Aquino EC, Alencar Rde C, Vencio. Salivary gland tumor: A review of 599 cases in a Brazilian population. Head Neck Pathol. 2009; 3:271-5. 
10. Barnes L, Eveson JW, Reichart P, Sidransky D. World Health Organization Classification of Tumours: Pathology and Genetics of Head and Neck Tumours. Lyon: IARC Press; 2005.

11. Nagarkar N., Bansal S. and Dass A. Singhal SK, Mohan H: Salivary gland tumors - our experience. Indian J Otolaryngol Head Neck Surg. 2004; 56(1): 31-34

12. Lukšić, I., Virag, M., Manojlović, S., Macan, D. (2012). Salivary gland tumours: 25 years of experience from a single institution in Croatia. $\mathrm{J}$ Craniomaxillofac Surg 2012; 40(3): e75-e81.

13. Subhashraj, K. (2008). Salivary gland tumors: a single institution experience in India. Br J Oral Maxillofac Surg 2008; 46(8): 635-638.

14. Tian Z, Li L, Wang L, Hu Y, Li J. Salivary gland neoplasms in oral and maxillofacial regions: a 23-year retrospective study of 6982 cases in an eastern Chinese population. Int J Oral Maxillofac Surg. 2010; 39: 235-242.
15. Jones AV, Craig GT, Speight PM, Franklin CD. The range and demographics of salivary gland tumours diagnosed in a UK population. Oral Oncol 2008; 44(4): 407-417.

16. Ochicha O, Malami S, Mohammed A, Atanda,A. A histopathologic study of salivary gland tumors in Kano, northern Nigeria. Indian $\mathbf{J}$ Pathol Microbiol2009; 52(4), 473.

17. Koch M, Zenk J, Iro H. Long-term results of morbidity after parotid gland surgery in benign disease. The Laryngoscope 2010; 120(4): 724730.

18. Rodriguez C P, Parvathaneni U, Méndez E, Martins RG. Salivary gland malignancies. Hematol Oncol Clin N Am 2015; 29: 1145-1157

19. Lombardi D, McGurk M, Vander Poorten V, Guzzo M, Accorona R, Rampinelli V, Nicolai P. Surgical treatment of salivary malignant tumors. Oral Oncol. 2017;65:102-113.

خلفية:ان الخة اورام الغدداللعابية تعد من الاورام المعقدة وتتكل 3\%من مجموع اورام الراس والرقبة سريريا هذه الاورام تكون

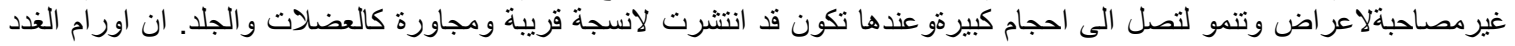

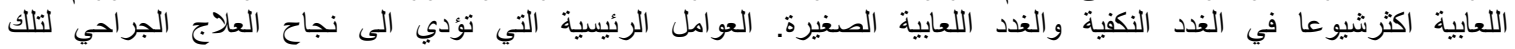

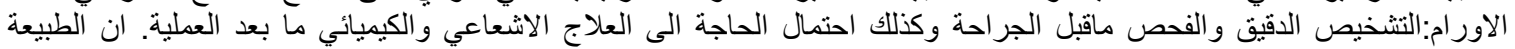

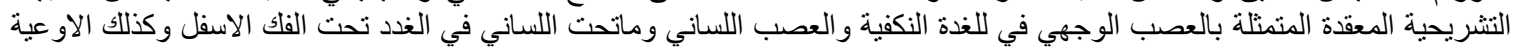

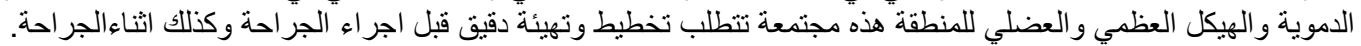

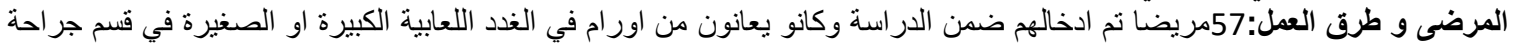

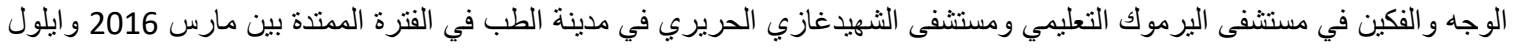
2017

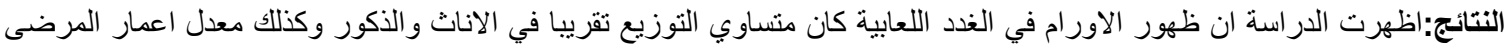

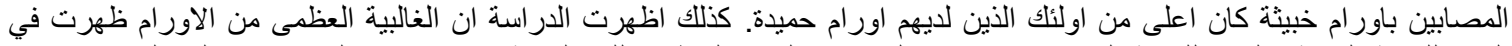

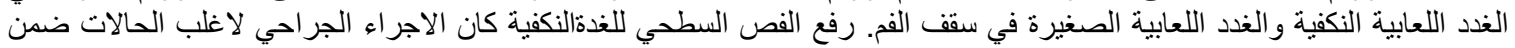

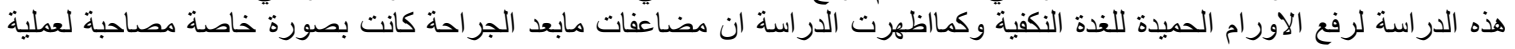

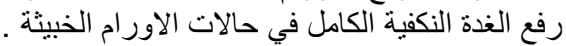
الاستنتاج:اظهرت الذرة اسةّ ان اغلب المضاعفات كانت مصاحبة لعمليات رفع الاور ام الخبيثة للغدد اللعابية بصورة خاص 